\title{
Computer Breakdown as a Stress Factor during Task Completion under Time Pressure: Identifying Gender Differences Based on Skin Conductance
}

\author{
René Riedl, ${ }^{1,2}$ Harald Kindermann, ${ }^{1}$ Andreas Auinger, ${ }^{1}$ and Andrija Javor ${ }^{3}$ \\ ${ }^{1}$ School of Management, University of Applied Sciences Upper Austria, Wehrgrabengasse 1-3, 4400 Steyr, Austria \\ ${ }^{2}$ Department of Business Informatics-Information Engineering, University of Linz, Linz, Austria \\ ${ }^{3}$ Department of Neurology and Psychiatry, Linz General Hospital, Linz, Austria
}

Correspondence should be addressed to René Riedl; rene.riedl@fh-steyr.at

Received 3 May 2013; Revised 2 September 2013; Accepted 10 September 2013

Academic Editor: Ian Oakley

Copyright (C) 2013 René Riedl et al. This is an open access article distributed under the Creative Commons Attribution License, which permits unrestricted use, distribution, and reproduction in any medium, provided the original work is properly cited.

In today's society, as computers, the Internet, and mobile phones pervade almost every corner of life, the impact of Information and Communication Technologies (ICT) on humans is dramatic. The use of ICT, however, may also have a negative side. Human interaction with technology may lead to notable stress perceptions, a phenomenon referred to as technostress. An investigation of the literature reveals that computer users' gender has largely been ignored in technostress research, treating users as "genderneutral." To close this significant research gap, we conducted a laboratory experiment in which we investigated users' physiological reaction to the malfunctioning of technology. Based on theories which explain that men, in contrast to women, are more sensitive to "achievement stress," we predicted that male users would exhibit higher levels of stress than women in cases of system breakdown during the execution of a human-computer interaction task under time pressure, if compared to a breakdown situation without time pressure. Using skin conductance as a stress indicator, the hypothesis was confirmed. Thus, this study shows that user gender is crucial to better understanding the influence of stress factors such as computer malfunctions on physiological stress reactions.

\section{Introduction}

Internet World Stats [1] and the International Telecommunication Union [2] indicated in 2012 that of the 7 billion people worldwide, 2.4 billion use the Internet. These two institutions report further impressive numbers, including the fact that 0.7 billion of the 1.8 billion households worldwide have a personal computer, and that there are 6 billion mobilecellular subscriptions and 1.2 billion mobile Web users.

Users of ICT, as well as organizations and society in general, have gained significant benefits through the adoption of technology (e.g., extensive possibilities for communication, increased access to information, and enhancements in productivity). The use of ICT, however, may also have a negative side. Human interaction with technology may lead to notable stress perceptions. This type of stress is referred to as technostress; a phenomenon that has been defined by the psychologist Craig Brod as "a modern disease of adaptation caused by an inability to cope with ... computer technologies in a healthy manner" [3, page 16]. Technostress, consequently, is both a psychological and a biological phenomenon.

A recent review on the biological effects of technostress indicates that perception of hassles during interaction with ICT (e.g., system breakdown and long and variable response times) may result in the activation of biological stress mechanisms that span a number of physiological systems, including the endocrine system, central nervous system, and autonomic nervous system [4]. Specifically, this review reveals that human interaction with ICT may lead to (i) elevations of stress hormones (e.g., adrenaline and cortisol) and other important precursor substances (e.g., alpha-amylase, adrenocorticotropic hormone), (ii) neuronal effects such as a decreased P300 amplitude indicating fatigue, and (iii) increased activation of the sympathetic division of the autonomic nervous system, including increased heart rate, blood pressure, skin conductance, and muscle tension. 
Importantly, repeated or chronic activation of biological stress mechanisms may result in detrimental health effects, including depression, abdominal obesity, suppression of immune function, chronic hypertension, and atherosclerosis [5]. Thus, technostress, and in particular perception of hassles during interaction with ICT, is a potential threat for human health $[4,6]$.

Research on stress perceptions during human interaction with ICT has revealed a number of insights into the measurement of technostress and into its antecedents and consequences [4]. Moreover, the efficacy of several countermeasures has been demonstrated based on biological measurement, including well-designed breaks during computer work [7] and users' regular execution of relaxation techniques [8]. However, despite these significant insights, investigation of the technostress literature reveals that computer users' gender has largely been ignored in scientific research. Thus, research has usually treated users as "gender-neutral," thereby neglecting one of the most fundamental biological characteristics.

Nonconsideration of users' gender in research on stress perceptions during human-computer interaction, however, is problematic for several reasons. First, gender, generally, is an important variable to explain variance in human perception, emotion, cognition, behavior, and underlying neurobiological mechanisms $[9,10]$. Second, gender has been identified as a variable that may considerably affect the influence of stress factors on the activation of biological systems [11, 12]. Third, it has been found that technology acceptance attitudes, as well as human behavior towards ICT, may vary significantly as a function of computer user gender [13-17]. Fourth, explicit calls have been made to consider a user's gender in interface design, because men and women have different abilities in the perception of colors and in processing of information and spatial navigation [18, 19]. Against this background, investigations into the effects of human interaction with ICT, particularly those with a focus on stress perceptions, are incomplete without a consideration of user gender.

Moreover, not only has the gender of users largely been neglected in technostress research but also the results of the few existing studies on the impact of user gender on stress perceptions are also diverging. Specifically, while Elder et al. [20] found that female users experience more technostress than males, Tarafdar et al. [21] found that men experience more technostress than women. Thus, there is no consistent pattern of research findings. Against the background of such thin and mixed evidence, it is of particular concern that empirical research addresses the role of user gender for technostress reactions.

\section{Theory and Hypothesis}

In general, humans use ICT to accomplish specific goals. For example, managers and staff members in organizations use computers and enterprise software to support operational workflows in order to increase decision-making performance, efficiency, and productivity. People in a private context, to state another example, use ICT to shop online because it is less time-consuming than traditional shopping. Accordingly, once a hassle such as system breakdown takes place, the accomplishment of a goal becomes threatened due to the malfunctioning of technology.

The tendency for ICT to continuously accelerate human activities (e.g., increasingly more people send text messages via smart phones and expect instantaneous reactions from their communication partners) aggravates the negative impact of technology malfunctioning on goal accomplishment, because humans are increasingly expected to execute their tasks in shorter periods, both in organizational and private contexts. Thus, goals typically have to be accomplished under considerable time pressure in today's highly computerized society [22].

But why should we expect different physiological stress responses to perception of computer hassles between men and women? We argue that such a difference originates from the fact that men are more sensitive to "achievement stress" [23], while women are more sensitive to "social rejection stress" [24]. Because ICT is typically used to attain a specific goal, whose accomplishment becomes threatened through malfunctioning of technology, particularly if someone acts under time pressure, we hypothesize that men exhibit higher levels of stress than women in cases of technology malfunctioning during the execution of a human-computer interaction task under time pressure.

This theorizing is supported by evidence showing that in situations involving performance failures, such as those in which humans use ICT for task accomplishment in a time-pressured environment, men perceive more stress than women, while in situations characterized by interpersonal conflicts, which are less related to a typical humanmachine interaction situation, women perceive more stress than men $[25,26]$. Moreover, in line with our theoretical argumentation, research has shown that men, in contrast to women, are more motivated by achievement needs and more directed towards individualistic tasks and goals, and generally more task-oriented than women and therefore exhibit more "masculine" traits such as assertiveness [15].

Explanations for gender differences in response to threat and stress usually draw upon evolution theory (for detailed discussions see, e.g., [24, 27]). Works based on the evolutionary account explain that the "fight-or-flight" response to stress characterizes the primary biological response to stress for both males and females, particularly by activating the hypothalamic-pituitary-adrenal (HPA) axis and the sympathetic division of the autonomic nervous system [28]. However, while males, in contrast to females, more often react with aggression to stress, women more often react with tending and befriending activities (tending involves nurturing activities with the goal to protect the self and offspring, and befriending is the establishment and maintenance of social networks that may support this tending process; [24]).

One major explanation why men should exhibit higher "achievement stress" than women draws upon evolutionary psychology. In essence, this theoretical account argues that, as the human species developed during the past millions of years, males acted mainly as hunters and protectors against predators, while females acted primarily as gatherers and 
cared for children (for details, see the literature cited in [19]). Because hunting and protecting activities imply physically aggressive behavior, while gathering and nurturing activities do not $[29,30]$, which in turn is closely related to strong activation of the sympathetic division of the autonomic nervous system, one would expect men, if compared to women, to exhibit more "achievement stress" [23]. Thus, we formulate the following hypothesis:

Male users exhibit higher levels of stress than female users in cases of system breakdown during the execution of a human-computer interaction task under time pressure.

\section{Methods}

We conducted a laboratory experiment in which users were confronted with a computer hassle, an unplanned system breakdown which took place during the execution of an online shopping task, either in a time-pressured environment (treatment condition) or without time pressure (control condition). We investigated whether such a hassle would result in skin conductance differences between male and female users. Skin conductance, also referred to as electrodermal activity (hereafter EDA), was used as a stress indicator because it reliably reflects activity of the sympathetic division of the autonomic nervous system [31]; the part of the human nervous system that is active during perception of arousal and stress [32, 33]. This measure is a well-established stress indicator in the human-computer interaction domain (e.g., $[34,35])$.

We decided to examine the breakdown of a computer system in the form of an error message, because it is one of the most significant and prevalent ICT hassles [36-38]. Once we had selected system breakdown as the type of stress factor to be investigated, we embedded this stressor into an online shop (sportswear). We developed the shop and its user interface from scratch for the experiment instead of using an existing and therefore potentially familiar system. Thus, we ruled out the possibility that experience with a specific interface affects our results.

The task for the subjects was to search for twelve specific products (e.g., clothing and footwear) and to put them into the shopping cart. The twelve products were illustrated and characterized on the basis of short product descriptions on a sheet of paper, which was placed next to the computer. Subjects were told that the objective of the experiment is to study the usability of the online shop.

Based on a between-subjects design, $N=77$ healthy persons (41 females) participated in the study (age: $M=23.45$ years, $\mathrm{SD}=4.25)$. All subjects gave written informed consent to participate in the study and were financially compensated for their participation. A review board approved the study. Each subject was randomly assigned either to the treatment group (system breakdown during task completion under time pressure, $N=40,22$ females) or the control group (system breakdown during task completion without time pressure, $N=37,19$ females).
Because the stress effects of system breakdown in a simulated Internet environment (here online shopping) may be related to subjects' actual Internet usage, computer anxiety, and age, it is important that there is no significant difference regarding these variables between the treatment and control groups and between males and females within each group. Because we recruited our subjects through advertisements at an Austrian university that mainly offers programs related to ICT, our sample was very homogeneous with respect to these variables.

Specifically, for Internet usage the ANOVA showed neither a significant difference between the treatment and control groups: $F(1,76)=0.003, P=0.908$ (treatment group: $1.38 \mathrm{M} / 0.45 \mathrm{SD}$; control group: $1.39 \mathrm{M} / 0.49 \mathrm{SD}$ ) nor did we observe a significant difference between males and females within each group (treatment: $F(1,39)=0.000, P=0.987$; males: $1.39 \mathrm{M} / 0.49$ SD, females: $1.39 \mathrm{M} / 0.49$ SD; control: $F(1$, $36)=0.681, P=0.415$; males: $1.44 \mathrm{M} / 0.43 \mathrm{SD}$, females: $1.32 \mathrm{M} / 0.48 \mathrm{SD}$; five-point Likert scale with 1 = "very often" and $5=$ "never"). With regard to computer anxiety, we neither observed significant differences between the treatment and control groups: $F(1,76)=0.015, P=0.903$ (treatment group: $1.38 \mathrm{M} / 0.59 \mathrm{SD}$; control group: $1.36 \mathrm{M} / 0.58 \mathrm{SD}$ ) nor between males and females within these two groups (treatment: $F(1$, 39) $=0.349, P=0.558$; males: $1.32 \mathrm{M} / 0.53 \mathrm{SD}$, females: $1.43 \mathrm{M} / 0.65$ SD; control: $F(1,36)=0.209, P=0.651$; males: $1.32 \mathrm{M} / 0.68$ SD, females: 1.41 M/0.49 SD; seven-point Likert scale with 1 = "totally disagree" and 7 = "totally agree", consisting of four items (e.g., I feel apprehensive about using computers.") [39, page 395]. Finally, we neither observed significant differences in subjects' age between the treatment and control groups: $F(1,76)=0.174, P=0.678$ (treatment group: $23.65 \mathrm{M} / 5.18 \mathrm{SD}$; control group: $23.24 \mathrm{M} / 3.01 \mathrm{SD}$ ) nor between males and females within these two groups (treatment: $F(1,39)=2.3, P=0.138$; males: $25.00 \mathrm{M} / 5.81 \mathrm{SD}$, females: $22.55 \mathrm{M} / 4.43 \mathrm{SD}$; control: $F(1,36)=0.686, P=0.413$; males: 23.67 M/2.99 SD, females: $22.84 \mathrm{M} / 3.06 \mathrm{SD}$ ).

Once a participant arrived in the room in which the experiment was conducted and was greeted, he or she was seated comfortably in front of a computer. Then, the experimenter attached two electrodes to the index and middle finger of the nondominant hand (volar surfaces of distal phalanges), assuring that the measurement device would not affect interaction with the system via the computer mouse. We used BioTrace+ (Mind Media BV, The Netherlands) to collect EDA responses during the experiment; the sample rate was $33 \mathrm{~Hz}$ and was measured in microsiemens $(\mu \mathrm{S})$, the unit for skin conductance and EDA, respectively. Once the electrodes were successfully attached and reliability of system functioning was checked, the experimenter explained the task in detail. Then, the subject started the online shopping task. To ensure reliability of EDA measurement, room temperature was kept at a constant level of $20^{\circ} \mathrm{C}$ throughout all experimental sessions.

In both groups (treatment, control), we implemented a system breakdown in the form of an error message which popped-up exactly 2.5 minutes after the participant's first click in the online shop. Moreover, to create "achievement stress" in the treatment group which would be similar to 


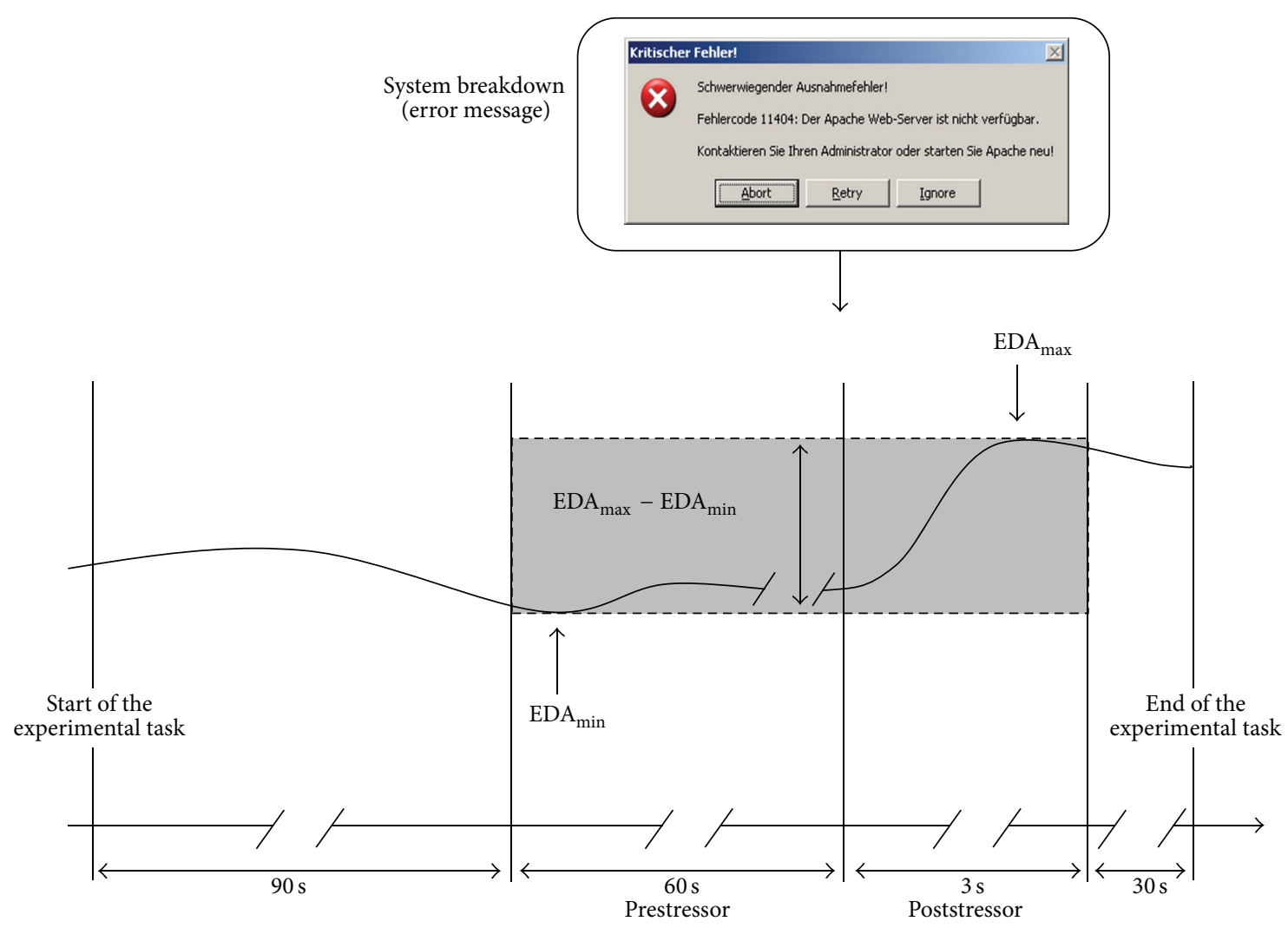

FIGURE 1: Collection and analysis of EDA data. Notes: The upper part of Figure 1 illustrates the stimulus, the error message which popped up 2.5 minutes after a participant's first click in the online shop. All stimulus material was presented in German. The error message contains the following text (literal translation): "Critical Error! Fatal exception error! Error code 11404: The ApacheWeb server is not available. Contact your administrator or restart Apache!" It was not possible for subjects to click away the error message, because the screen view was frozen. Time intervals that were used for data analyses are illustrated in gray background color, namely, 60 seconds before stimulus onset (prestressor phase) and 3 seconds after stimulus onset (poststressor phase). Changes in electrodermal activity (EDA) in response to discrete events can be expected within a time interval of 3 seconds [33].

real-life environments, time pressure was implemented (i) by informing the participant about the fact that he or she was expected to accomplish the task within three minutes and by (ii) showing a digital time counter which was embedded into the user interface, positioned in the upper left corner to guarantee high visibility. In the control group, participants were informed that they would have as much time as they needed to complete the task; moreover, there was no time counter embedded into the user interface.

Skin conductance responses to discrete events (in the present study system breakdown) may vary significantly between individuals. Thus, baseline measurement, as well as normalization of data, is crucial. Our approach for data collection and normalization is illustrated in Figure 1.

Each participant started his or her experimental session with the first click in the online shop. Even though EDA measurement took place during the execution of the entire experimental session, we did not analyze data from the first 90 seconds of task execution because this data was potentially affected by artifacts, including communication with the experimenter who explained the task before the beginning of the task. Time intervals that were used for data analyses are illustrated in gray background color in Figure 1, namely, the 60 -second interval before stimulus onset (prestressor phase) and the 3-second interval after stimulus onset (poststressor phase). This latter interval was used because electrodermal response to discrete events can be expected within a time interval of 3 seconds [33], a fact that we confirmed by analysis of data from five subjects in a pretest (data not used for the main study).

For each subject, we had 1,980 measurement points $(60 \mathrm{sec} \times 33 \mathrm{~Hz})$ in the prestressor phase and 99 measurement points in the poststressor phase. Following an established procedure for preprocessing of physiological data [33], which has also been applied in human-computer interaction research based on EDA measurement [40], we normalized each measurement point $\left(\mathrm{EDA}_{i}\right)$ as follows: $\mathrm{EDA} \%=\left(\mathrm{EDA}_{i}-\right.$ $\left.\mathrm{EDA}_{\min }\right) /\left(\mathrm{EDA}_{\max }-\mathrm{EDA}_{\text {min }}\right)$. For each subject, we used all EDA\%-values to calculate the mean, both for the pre- and poststressor phases, resulting in two final values for each subject. These two values were used for statistical analyses, performed based on SPSS. 


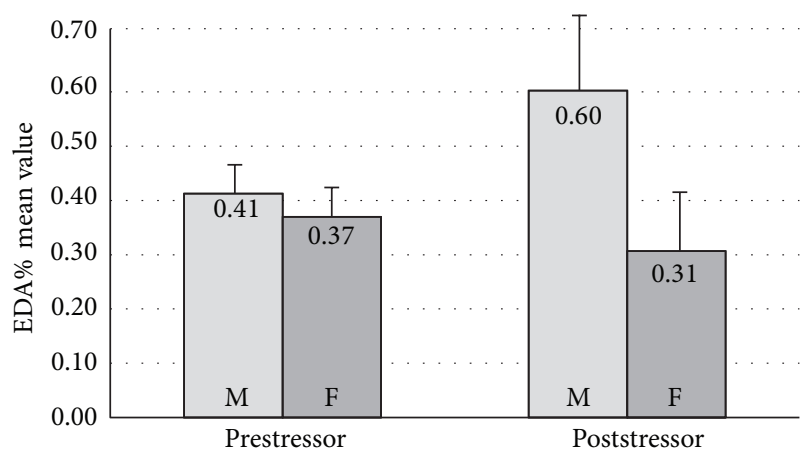

(a)

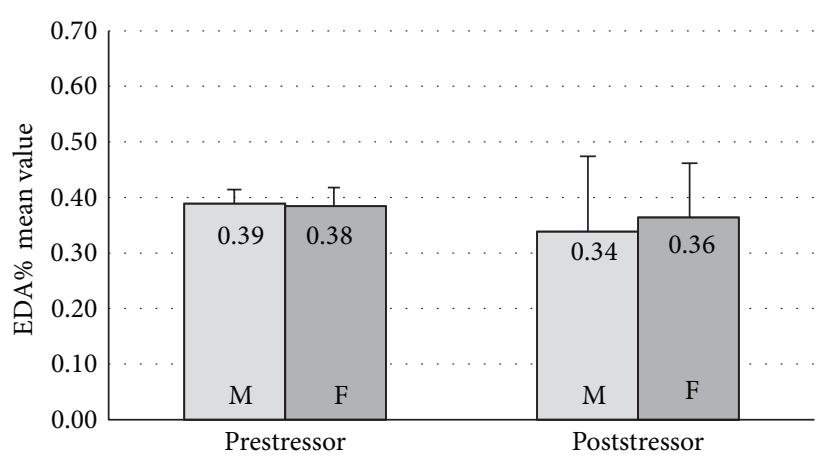

(b)

Figure 2: Results (treatment versus control condition). Notes: $\mathrm{F}=$ Female, $\mathrm{M}=$ Male. Panel (a) illustrates the results of the treatment condition (time-pressured environment), panel (b) illustrates the results of the control condition (no time pressure). Panel (a) The EDA mean values of males are significantly different between the prestressor $(0.41)$ and poststressor $(0.60)$ phases $(P=0.020)$; also, in the poststressor phase the EDA mean values of males (0.60) are significantly different from the EDA mean values of females $(0.31)(P=0.000)$; all other comparisons of EDA mean values do not yield statistically significant differences. Panel (b) There are no statistically significant differences. Error bars show confidence intervals at the $95 \%$-level.

\section{Results}

As illustrated in Figure 2, our data support the hypothesis that men exhibit higher levels of stress than women in case of system breakdown during the execution of a specific humancomputer interaction task (i.e., simulated online shopping) under time pressure.

Specifically, there was no significant difference between the prestressor EDA mean values between males (0.41) and females $(0.37)$ in the treatment group $(F(1,39)=1.599, P=$ $0.214)$, indicating that up until emergence of system breakdown (i.e., 60 seconds of online shopping without occurrence of any hassle), skin conductance of men resembled that of women. However, we observed a significant increase of the EDA mean value in male users as a response to system breakdown in the treatment condition (from 0.41 to $0.60, F(1$, 17) $=6.583, P=0.020$ ), while we did not observe such a reaction in women (the value even slightly decreased from 0.37 to $0.31, F(1,21)=0.951, P=0.341)$. This indicates that males, but not females, exhibit a strong stress reaction to system malfunctioning in a time-pressured human-computer interaction task. Also, a comparison of males' and females' EDA mean values in the poststressor phase in the treatment condition yields a statistically significant difference $(0.60$ versus $0.31, F(1,39)=14.498, P=0.000)$.

In the control condition, we did not observe statistically significant differences-neither between the prestressor and poststressor phases (male: 0.39 versus $0.34, F(1,17)=0.720$, $P=0.408$; female: 0.38 versus $0.36, F(1,18)=0.101, P=0.754)$ nor within the prestressor (male: 0.39 versus female: $0.38, F(1$, $36)=0.023, P=0.881$ ) and poststressor phases (male: 0.34 versus female: $0.36, F(1,36)=0.096, P=0.759)$.

\section{Discussion}

Our study reveals that men exhibit significantly higher levels of stress than women in case of system breakdown during the execution of a specific human-computer interaction task (i.e., simulated online shopping) under time pressure. Specifically, we found that males' skin conductance, reflecting activation of the sympathetic division of the autonomic nervous system, sharply increased in response to perception of a computer problem in a time-pressured environment. This suggests that males, more than females, are sensitive to computer hassles in today's hectic environment.

This result is in line with findings from a recent survey study, in which it is indicated that men report higher levels of technostress perceptions than women [21]. Importantly, the present investigation provides biological evidence for this self-reported difference, thereby complementing the perceptual/behavioral level of research with the physiological one.

Our result is also in line with the conclusion of a recent review article on gender differences in physiological reactivity to acute psychological stress (e.g., Trier Social Stress Test), namely, that "males generally show higher levels of ... ANS (autonomic nervous system) reactivity" [41, page 1135]. Moreover, results of a recent brain imaging experiment indicate that in the face of stressful stimuli (i.e., negative pictures) activity in stress-related brain regions (hypothalamus, amygdala, and anterior cingulate gyrus) was higher in men than in women [42]. This not only provides support for the data presented in this paper, but also for the basic rationale underlying this paper's theorizing; namely, that the male stress system, in contrast to the female one, reacts more strongly to threatening and negative situations under performance conditions. This general mechanism seems to be independent from the type of threatening stimulus, being it a dangerous-looking face, or the breakdown of a computer system, both of which may prevent humans from goal accomplishment, thereby being motivationally more relevant for males rather than females.

Despite the fact that our results are in line with predictions of gender differences in stress reactions, they seem to be 
contradictory to the general notion that women, in contrast to men, perceive more stress. Importantly, this notion is substantiated by evidence showing that women, if compared to men, have an increased risk for stress-related illnesses such as anxiety disorders and depression [12]. However, research indicates that for a more complete understanding of gender differences in stress reactions, it is of particular importance to consider the nature of a stress factor [43]. Specifically, it is argued that women are more sensitive to stressors related to social interaction (e.g., divorce, death in the immediate family, and serious illness of a close friend), while men are more sensitive to nonsocial stressors (e.g., major change in financial status and alterations in work pressure or workload) [43]. Obviously, malfunctioning of ICT is a nonsocial stressor. Thus, our results substantiate the notion that the nature of a stressor is a major factor explaining differential stress responses in men and women.

Historically, during the epochs of human evolution, a gender-specific division of labor existed where males' main responsibility was hunting and females specialized in gathering. Because hunting is related to physically aggressive behavior, while gathering is not, men, much more than women, exhibit activation of the sympathetic division of the autonomic nervous system once they are prevented from accomplishment of a specific goal (e.g., hunting down prey). Thus, men, on average, have higher levels of "achievement stress" than women [23]. Because repeated or chronic activation of the sympathetic system may lead to detrimental health effects (e.g., hypertension, atherosclerosis), the present study suggests that effective technostress countermeasures are of particular relevance for men. Even though research already identified physiologically effective countermeasures (e.g., well-designed breaks during computer work [7] and users' regular execution of relaxation techniques [8]), future studies could evaluate the efficacy of further countermeasures and coping strategies.

Generally, two broad categories of coping strategies exist: problem-focused and emotion-focused [31]. The former strategy attempts to change the person-environment realities related to a stressful situation (e.g., increasing computer knowledge to elevate the controllability of possible ICT malfunctions); the latter seeks to reduce negative feelings by changing the appraisal of a given stressful situation (e.g., downplaying the possible negative effects of computer breakdown on the accomplishment of a goal) [44]. Independent of a user's chosen coping strategy, it would be rewarding to investigate gender differences in the effects of different strategies on changes in activity of the sympathetic division of the autonomic nervous system.

\section{Conclusion}

Based on theories which explain that men are more sensitive to "achievement stress," while women are more sensitive to "social rejection stress," this study found that male computer users exhibit higher levels of stress than female users in cases of computer system breakdown during the execution of an online shopping task under time pressure. Users of
ICT, as well as organizations and society in general, have gained notable benefits through the use of computers, the Internet, smart phones, and other technologies. The use of ICT, however, may also result in notable stress perceptions, a phenomenon referred to as technostress, which can also have detrimental health implications for users $[4,6]$. We have shown that users' gender must not be ignored in technostress research. Treating users as "genderless entities" would constitute a great disservice, both for theory and practice.

All in all, while we believe that the present study is an important step towards a better understanding of gender differences in stress perceptions during human-computer interaction in a time-pressured environment, further studies are necessary to better understand gender differences in this domain. Moreover, as already explained by other studies on gender and ICT usage (e.g., [13]), we emphasize that not all men are of one kind and all women of another. Rather, we argue that on average men and women differ in their stress reactions to computer breakdown during execution of a human-computer interaction task in a time-pressured environment. Finally, we underline that technostress is a highly complex phenomenon $[4,45]$, of which we have investigated one specific aspect only in the present study (system breakdown). It will therefore be rewarding to see what further insights future investigations will reveal.

\section{Conflict of Interests}

The authors declare that there are no conflict of interests associated with this work.

\section{Acknowledgments}

The authors would like to thank the Senior Editor, Ian Oakley, and three anonymous reviewers for their excellent work in providing guidance on ways to improve the paper.

\section{References}

[1] Internet World Stats, http://www.internetworldstats.com/.

[2] International Telecommunication Union, http://www.itu.int/.

[3] C. Brod, Technostress: The Human Cost of the Computer Revolution, Addison-Wesley, Reading, Mass, USA, 1984.

[4] R. Riedl, "On the biology of technostress: literature review and research agenda," The DATA BASE for Advances in Information Systems, vol. 44, no. 1, pp. 18-55, 2013.

[5] B. S. McEwen, "Protective and damaging effects of stress mediators: central role of the brain," Dialogues in Clinical Neuroscience, vol. 8, no. 4, pp. 367-381, 2006.

[6] B. B. Arnetz and M. Berg, "Melatonin and adrenocorticotropic hormone levels in video display unit workers during work and leisure," Journal of Occupational and Environmental Medicine, vol. 38, no. 11, pp. 1108-1110, 1996.

[7] W. Boucsein and M. Thum, "Design of work/rest schedules for computer work based on psychophysiological recovery measures," International Journal of Industrial Ergonomics, vol. 20, no. 1, pp. 51-57, 1997. 
[8] B. B. Arnetz, "Techno-stress: a prospective psychophysiological study of the impact of a controlled stress-reduction program in advanced telecommunication systems design work," Journal of Occupational and Environmental Medicine, vol. 38, no. 1, pp. 5365, 1996.

[9] L. Cahill, "Why sex matters for neuroscience," Nature Reviews Neuroscience, vol. 7, no. 6, pp. 477-484, 2006.

[10] K. P. Cosgrove, C. M. Mazure, and J. K. Staley, "Evolving knowledge of sex differences in brain structure, function, and chemistry," Biological Psychiatry, vol. 62, no. 8, pp. 847-855, 2007.

[11] B. M. Kudielka, D. H. Hellhammer, and C. Kirschbaum, "Sex differences in human stress response," in Encyclopedia of Stress, G. Fink, T. Cox, E. R. de Kloet et al., Eds., Academic Press, San Diego, Calif, USA, 2000.

[12] B. M. Kudielka and C. Kirschbaum, "Sex differences in HPA axis responses to stress: a review," Biological Psychology, vol. 69, no. 1, pp. 113-132, 2005.

[13] D. Gefen and C. M. Ridings, "If you spoke as she does, sir, instead of the way you do: a sociolinguistics perspective of gender differences in virtual communities," The DATA BASE for Advances in Information Systems, vol. 36, no. 2, pp. 78-92, 2005.

[14] D. Gefen and D. W. Straub, "Gender differences in the perception and use of e-mail: an extension to the technology acceptance model," MIS Quarterly, vol. 21, no. 4, pp. 389-400, 1997.

[15] V. Venkatesh and M. G. Morris, "Why don't men ever stop to ask for directions? Gender, social influence, and their role in technology acceptance and usage behavior," MIS Quarterly, vol. 24, no. 1, pp. 115-136, 2000.

[16] A. Broos, "Gender and information and communication technologies (ICT) anxiety: male self-assurance and female hesitation," Cyberpsychology and Behavior, vol. 8, no. 1, pp. 21-31, 2005.

[17] B. E. Whitley Jr., "Gender differences in computer-related attitudes and behavior: a meta-analysis," Computers in Human Behavior, vol. 13, no. 1, pp. 1-22, 1997.

[18] R. Riedl, M. Hubert, and P. Kenning, "Are there neural gender differences in online trust? An fMRI study on the perceived trustworthiness of eBay offers," MIS Quarterly, vol. 34, no. 2, pp. 397-428, 2010.

[19] E. Stenstrom, P. Stenstrom, G. Saad, and S. Cheikhrouhou, "Online hunting and gathering: an evolutionary perspective on sex differences in website preferences and navigation," IEEE Transactions on Professional Communication, vol. 51, no. 2, pp. 155-168, 2008.

[20] V. B. Elder, E. P. Gardner, and S. R. Ruth, "Gender and age in technostress: effects on white collar productivity," Government Finance Review, vol. 3, no. 6, pp. 17-21, 1987.

[21] M. Tarafdar, Q. Tu, T. S. Ragu-Nathan, and B. S. Ragu-Nathan, "Crossing to the dark side: examining creators, outcomes, and inhibitors of technostress," Communications of the ACM, vol. 54, no. 9, pp. 113-120, 2011.

[22] K. Roberts, "Work-life balance-the sources of the contemporary problem and the probable outcomes: a review and interpretation of the evidence," Employee Relations, vol. 29, no. 4, pp. 334-351, 2007.

[23] L. R. Stroud, P. Salovey, and E. S. Epel, "Sex differences in stress responses: social rejection versus achievement stress," Biological Psychiatry, vol. 52, no. 4, pp. 318-327, 2002.

[24] S. E. Taylor, L. C. Klein, B. P. Lewis, T. L. Gruenewald, R. A. R. Gurung, and J. A. Updegraff, "Biobehavioral responses to stress in females: tend-and-befriend, not fight-or-flight," Psychological Review, vol. 107, no. 3, pp. 411-429, 2000.

[25] R. M. Eisler and J. R. Skidmore, "Masculine gender role stress: scale development and component factors in the appraisal of stressful situations," Behavior Modification, vol. 11, no. 2, pp. 123-136, 1987.

[26] B. L. Gillespie and R. M. Eisler, "Development of the feminine gender role stress scale: a cognitive-behavioral measure of stress, appraisal, and coping for women," Behavior Modification, vol. 16, no. 3, pp. 426-438, 1992.

[27] A. Campbell, "Sex differences in aggression," in Oxford Handbook of Evolutionary Psychology, L. Dunbar and L. Barrett, Eds., Oxford University Press, Oxford, UK, 2007.

[28] C. Tsigos and G. P. Chrousos, "Hypothalamic-pituitary-adrenal axis, neuroendocrine factors and stress," Journal of Psychosomatic Research, vol. 53, no. 4, pp. 865-871, 2002.

[29] S. V. Budaev, "Sex differences in the Big Five personality factors: testing an evolutionary hypothesis," Personality and Individual Differences, vol. 26, no. 5, pp. 801-813, 1999.

[30] N. H. Hess and E. H. Hagen, "Sex differences in indirect aggression: psychological evidence from young adults," Evolution and Human Behavior, vol. 27, no. 3, pp. 231-245, 2006.

[31] R. S. Lazarus and S. Folkman, Stress, Appraisal, and Coping, Springer, New York, NY, USA, 1984.

[32] W. Boucsein, Electrodermal Activity, Plenum Press, New York, NY, USA, 1992.

[33] M. E. Dawson, A. M. Schell, and D. L. Filion, "The electrodermal system," in Handbook of Psychophysiology, J. T. Cacioppo, L. G. Tassinary, and G. G. Berntson, Eds., Cambridge University Press, Cambridge, UK, 3rd edition, 2007.

[34] W. Kuhmann, W. Boucsein, F. Schaefer, and J. Alexander, "Experimental investigation of psychophysiological stressreactions induced by different system response times in humancomputer interaction," Ergonomics, vol. 30, no. 6, pp. 933-943, 1987.

[35] M. Trimmel, M. Meixner-Pendleton, and S. Haring, "Stress response caused by system response time when searching for information on the internet," Human Factors, vol. 45, no. 4, pp. 615-621, 2003.

[36] R. A. Hudiburg, "Psychology of computer use: VII. Measuring technostress: computer-related stress," Psychological Reports, vol. 64, pp. 767-772, 1989.

[37] R. A. Huidiburg, "Psychology of computer use: XVII. The computer technology hassles scale: revision, reliability, and some correlates," Psychological Reports, vol. 65, no. 3, pp. 13871394, 1989.

[38] R. Riedl, H. Kindermann, A. Auinger, and A. Javor, "Technostress from a neurobiological perspective-system breakdown increases the stress hormone cortisol in computer users," Business \& Information Systems Engineering, vol. 4, no. 2, pp. 61-69, 2012.

[39] J. B. Thatcher and P. L. Perrewé, "An empirical examination of individual traits as antecedents to computer anxiety and computer self-efficacy," MIS Quarterly, vol. 26, no. 4, pp. 381396, 2002.

[40] P. M. Léger, F. D. Davis, J. Perret, and M. Dunaway, Psychophysiological Measures of Cognitive Absorption, SIGHCI 2010 Proceedings, Paper 9, 2010.

[41] S. Ordaz and B. Luna, "Sex differences in physiological reactivity to acute psychosocial stress in adolescence," Psychoneuroendocrinology, vol. 37, no. 8, pp. 1135-1157, 2012. 
[42] J. M. Goldstein, M. Jerram, B. Abbs, S. Whitfield-Gabrieli, and N. Makris, "Sex differences in stress response circuitry activation dependent on female hormonal cycle," Journal of Neuroscience, vol. 30, no. 2, pp. 431-438, 2010.

[43] M. P. Matud, "Gender differences in stress and coping styles," Personality and Individual Differences, vol. 37, no. 7, pp. 14011415, 2004.

[44] R. A. Hudiburg and J. R. Necessary, "Coping with computerstress," Journal of Educational Computing Research, vol. 15, no. 2, pp. 113-124, 1996.

[45] M. Tarafdar, Q. Tu, and T. Ragu-Nathan, "Impact of technostress on end-user satisfaction and performance," Journal of Management Information Systems, vol. 27, no. 3, pp. 303-334, 2010. 

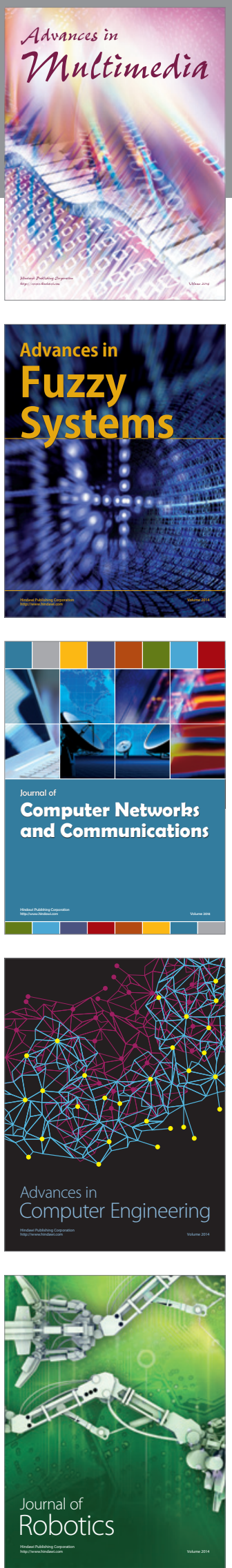

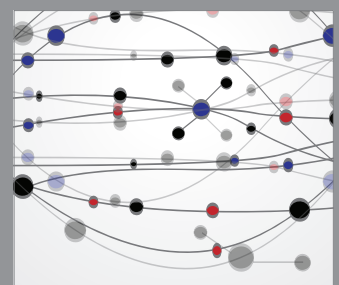

The Scientific World Journal
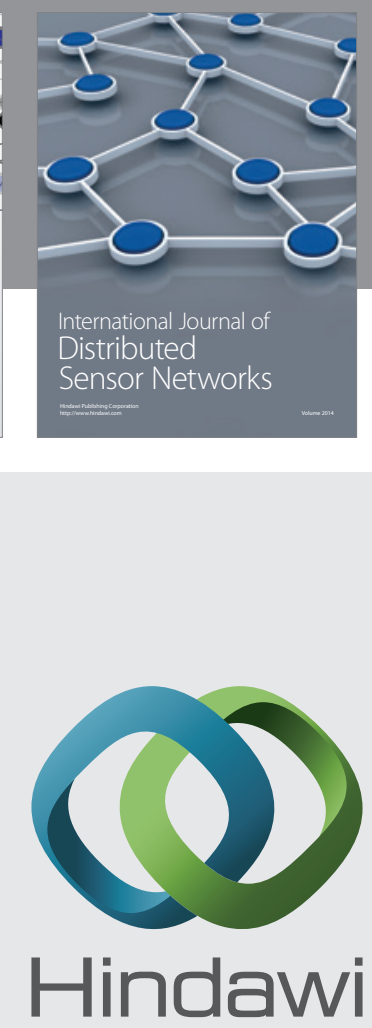

Submit your manuscripts at

http://www.hindawi.com
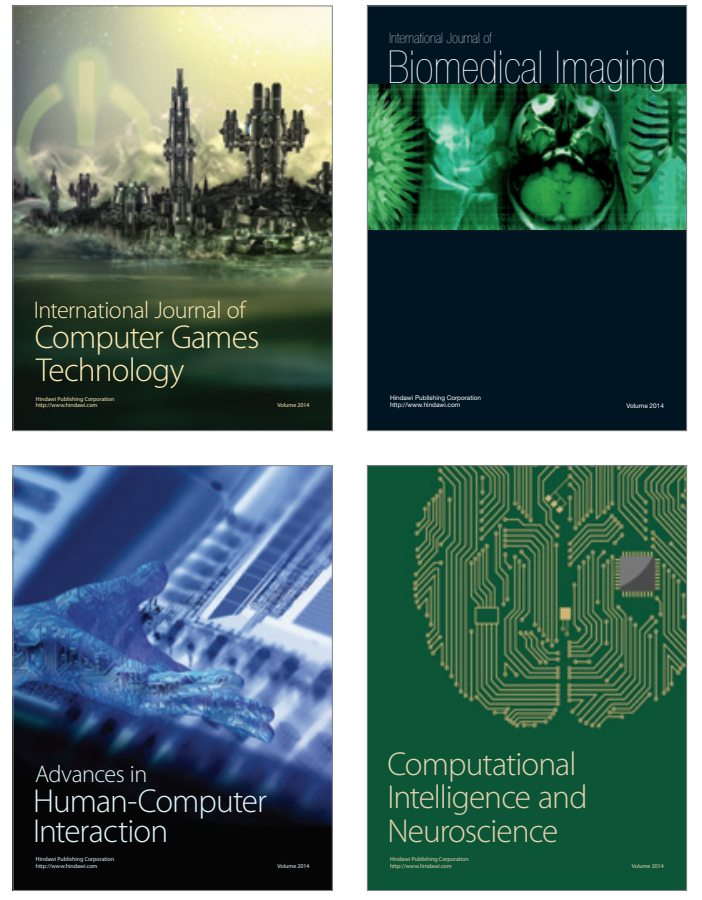
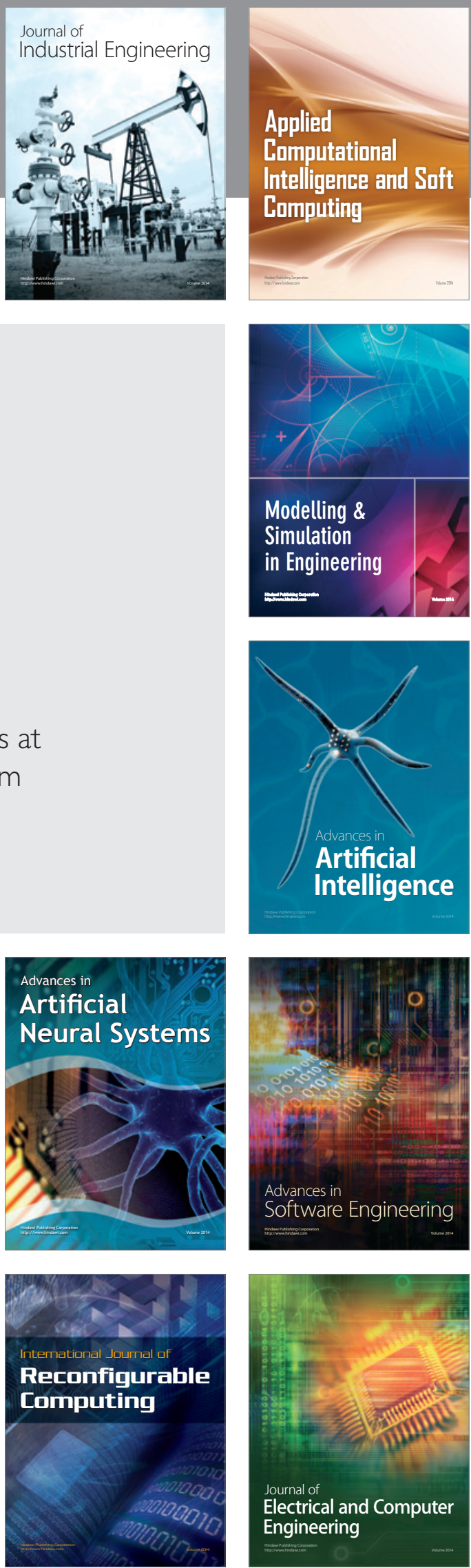